\title{
Physicochemical Traits, Fatty Acid and Free Amino Acid Compositions of Two-way Crossbred Pork Belly
}

\author{
Dong-Gyun Lim ${ }^{1}$, Kyung-Tai Kim², Kyung-Haeng Lee ${ }^{3}$, Kang-Seok Seo, and Ki-Chang Nam* \\ Department of Animal Science and Technology, Sunchon National University, Suncheon 540-742, Korea \\ ${ }^{1}$ Department of Health Administration, Jinju Health College, Jinju 660-757, Korea \\ ${ }^{2}$ Breeding Pig Improvement Center, NACF, Yeonggwang 513-812, Korea \\ ${ }^{3}$ Department of Food and Nutrition, Korea National University of Transportation, Jeungpyeong 368-701, Korea
}

\begin{abstract}
This study was conducted to determine the meat quality characteristics of pork belly from 3 different two-way crossbreeds of Yorkshire $\times$ Landrace (YL), Yorkshire $\times$ Berkshire (YB), and Yorkshire $\times$ Chester White (YC), which were domesticated for Korean consumers. Twenty pigs from each crossbreed (total $n=60$ ) were randomly selected when they reached the 110$120 \mathrm{~kg}$ range of market weight, slaughtered, and cooled at $0^{\circ} \mathrm{C}$ for $24 \mathrm{~h}$. The pork bellies on the left side of the cooled carcasses were then sampled and analyzed. The $\mathrm{pH}$ of pork bellies was the lowest in $\mathrm{YC}$ among the crossbreds. There was no significant difference in fat content by crossbred, but YB bellies had the lowest moisture content $(p<0.05)$. The cooking loss of YB bellies was lower than those of others $(p<0.05)$. The TBARS values in YB was significantly higher than those of the others at $14 \mathrm{~d}$. YL bellies had a higher percentage of stearic acid, oleic acid, and MUFA than the other breeds, while YB and YC had a higher percentage of myristic acid, linoleic acid, linolenic acid, and $\mathrm{n}-6$ fatty acids than the YB $(p<0.05)$. PUFA content and $\mathrm{P} / \mathrm{S}$ were significantly higher in $\mathrm{YC}$ compared with $\mathrm{YL}$. Except for arginine, the concentrations of most free amino acids were higher in YB bellies than in others, $(p<0.05)$. Sensory evaluation scores of bellies were higher for YC than for other breeds $(p<0.05)$.
\end{abstract}

Key words: crossbred, pork belly, meat quality, fatty acid, free amino acid, sensory

\section{Introduction}

Pork quality is a function of multi-factors including breed, feeding scheme, and pre-and post-slaughter managements. However, breed could be attributed as to the most significant single factor related to intramuscular fat, water holding capacity, color and tenderness (Sellier and Monin, 1994). There are number of studies have attempted to identify the best premium pig breed in terms of productivity, carcass and eating quality (Newcom et al., 2004). Individual species in pigs has different traits. Berkshire breed had thin muscle fiber and was excellent in water holding capacity (WHC) (Suzuki et al., 2003). Berkshire breed had high contents of amino acids, and lower moisture content, cooking, and drip loss (NPPC, 1995). On the other hand, Yorkshire and Landrace car-

\footnotetext{
*Corresponding author: Ki-Chang Nam, Department of Animal Science and Technology, Sunchon National University, Suncheon 540-745, Korea. Tel: 82-61-750-3231, Fax: 82-61-750-3230, E-mail: kichang@scnu.kr
}

casses had a thin subcutaneous fat layer, large hams, and high muscularity (Ruusunen et al., 2012).

Crossbreeding is extensively used to increase the total efficiency of pig production and also to improve the quantity and quality of the meat (Bennet et al., 1983). Crossbred advantage is maximized in an individual born from a three-way cross and is twice as large as in the progeny of a backcross (Langlois and Minvielle, 1989). A few studies investigated the effect of genetic factors on meat quality (Ruusunen et al., 2012; Suzuki et al., 2003). Kim et al. (2006) mentioned that Landrace and Yorkshire $\times$ Duroc (LYD) pigs had lower shear force values and higher WHC compared with other breeds. In Korea, commercial pigs are currently three-way crosses with LYD. They are known for more rapid growth rate, bigger litter size, and higher yields than those reported for improved breeds in Korea (Hong et al., 2001).

In recent years, pork bellies are the most demanding and popular cuts in most Korean meat consumers and consequently their retail prices are much higher than other cuts. Although there have been increasing trials to 
produce pork species with high meat quality, previous research on comparison between the breed and meat quality has only assessed in the parts of loins. Furthermore, it is not clear whether two-way crossbreeding in swine affects the final meat quality of the three-way crossbreed. It is imperative to select appropriate two-way crossbreeds to produce more competitive three-way crossbreed replacing commercial LYD, in especially highly preferred pork cut bellies. Lipid compositions are known for several muscles within the species (Alasnier et al., 1996; Leseigneur-Meynier and Ganderner, 1991), but little is known about free amino acid composition in the muscles of crossbreeding in pigs. A research should be done using different type of mating system or crossbreds on pork quality parameters such as fatty acid, amino acid and sensory parameter to fulfill consumer's need in terms of new productive scheme for optimal meat quality.

There is little information on meat quality traits of twoway crossbreds in pork belly known for highly preferred pork cut in Korea. Therefore, the objective of this study was to compare the pork bellies from two-way crossbreds of Yorkshire $\times$ Landrace (YL), YorkshirexBerkshire (YB), and Yorkshire $\times$ Chester White (YC) in terms of their physicochemical and sensory characteristics.

\section{Materials and Methods}

\section{Animals, sample collection, and preparation for analysis}

A total of 60 gilts (female pig) were evaluated from three different crossbreeding schemes including Yorkshire $\times$ Landrace $(\mathrm{YL})$, Yorkshire $\times$ Berkshire $(\mathrm{YB})$, and Yorkshire $\times$ Chester White (YC), with 20 animals in each scheme. YL, YB, and YC were selected as most potent two-way breed candidate according to the growth and production scores by NongHyun breeding pig improvement center (Yeonggwang, Korea). Thus the pigs were raised and fed under the standardized same feed conditions. Twenty pigs from each crossbred were randomly selected from 110-120 kg range of marketing weight, slaughtered, and cooled at $0^{\circ} \mathrm{C}$ for $24 \mathrm{~h}$ in a chilling room. The parts of bellies on the left side of the cooled carcasses were used to measure meat quality parameters. All samples were placed in vacuum bags and subsequently transported to the laboratory. And they were stored and frozen at $-18^{\circ} \mathrm{C}$ in deep freezer until they were analyzed. All samples were used at the same location on the bellies over the middle portion and excess fat and bone were removed from the belly muscles. Prior to analysis, the samples were thawed overnight at $4^{\circ} \mathrm{C}$.

\section{pH measurement}

The $\mathrm{pH}$ of samples was determined with a $\mathrm{pH}$ meter (Orion 2 Star, Thermo scientific, Beverly, MA, USA). The $\mathrm{pH}$ values of pork belly were measured by blending a $3 \mathrm{~g}$ sample with $27 \mathrm{~mL}$ distilled water for $60 \mathrm{~s}$ in a homogenizer (Polytron PT 10-35 GT, Kinematica AG, Switzerland). The electrode was calibrated with $\mathrm{pH} 4.01$ and 7.00 standard buffers equilibrated at $25^{\circ} \mathrm{C}$ for the measurements.

\section{Moisture and fat content}

The samples were trimmed of all external fat prior to analysis. Moisture content was obtained with a slightly modified method of AOAC (2000). The total moisture content of $3 \mathrm{~g}$ of samples placed in aluminum moisture dishes were determined from their pre-dry and dry weights (dried in an air oven at $104^{\circ} \mathrm{C}$ for $24 \mathrm{~h}$ ) and expressed as the percentage of pre-dry weight and gram water per gram dry weight. The moisture content was determined in triplicate on each sample. Fats were extracted from $5 \mathrm{~g}$ of meat with chloroform/methanol (2:1), according to the method described by Folch et al. (1957).

\section{Drip and cooking loss}

Drip loss and cooking loss were analyzed by the method described by the procedure of Kang et al. (2011). Percentage drip loss was determined by dividing the weight loss during thawing by the frozen weight of each sample. For cooking loss, after the samples were thawed and boned, they were weighed and cooked in a electric grill (HD 6320, Philips Electronics, Netherlands), until they reached a final internal temperature of $72 \pm 2^{\circ} \mathrm{C}$. Percentage cooking loss was determined by dividing the weight loss during cooking by the pre-cooked weight.

\section{Instrumental measurement of color}

The surface color value of the pork belly samples were measured by the CIE L*, a* and $b^{*}$ system using a Minolta chromameter (Model CR-410, Minolta Co. Ltd., Japan), with measurements standardized with respect to a white calibration plate $\left(L^{*}=89.2, a^{*}=0.921, b^{*}=0.783\right)$ after 30 min blooming at room temperature. Color measurements for each of three replicates, always trying to avoid area with excess fat were taken and the value was recorded.

\section{Shear force measurement}

Shear force values were analyzed by the method des- 
cribed by the procedure of Kang et al. (2011). The pork belly samples were prepared a cubic form $(20 \times 20 \times 10$ $\mathrm{mm}$ ) and heated during $90 \mathrm{~s}$ in electrical grill (Nova EMG-533, 1,400W, Evergreen enterprise, Korea). Internal temperature of the samples during heating was $72 \pm 2^{\circ} \mathrm{C}$ and then cooled for $30 \mathrm{~min}$ at room temperature. Each sample was cut perpendicular to the longitudinal orientation of the muscle fiber with a Warner-Bratzler shear attachment on a texture analyzer (TA-XT2i, Stable Micro System Ltd., U.K.), and measured the maximum shear force (unit; $\mathrm{kg}$ ). Test and pre-test speeds were set at $2.0 \mathrm{~mm} / \mathrm{s}$. Post-test speeds were set at $5.0 \mathrm{~mm} / \mathrm{s}$. Data were collected and analyzed from the shear force values to obtain for the maximum force required to shear through each sample.

\section{WHC}

WHC was determined in duplicate in fresh meat $(5 \mathrm{~g})$ using the procedure of Uttaro et al. (1993), with minor modifications. These were placed in pre-weighed centrifugal microfilters (Centrex glass fiber filter, Schleicher \& Schuell, USA), without the collection vial, and weighed. The vial was attached, and tubes centrifuged at $18,800 \mathrm{~g}$ for $15 \mathrm{~min}$. The collection vial containing the expressed fluid was removed, and tubes reweighed, enabling water loss to be calculated by difference.

\section{TBARS (2-thiobarbituric acid reactive substance)}

TBARS values were determined at various storage times. The TBARS of pork belly samples were analyzed by the modification method described by the procedure of Ahn et al. (1998). A $5 \mathrm{~g}$ pork belly sample was homogenized using a homogenizer (Polytron PT 10-35 GT, Kinematica Co., Switzerland) with $15 \mathrm{~mL}$ of distilled water for $2 \mathrm{~min}$ and then transferred to $100 \mathrm{~mL}$ falcon tube. $1 \mathrm{~mL}$ of solution was placed in test tubes and $50 \mathrm{~mL}$ buylated hydroxytoluene $(7.2 \%$ in ethanol, w/v) and $2 \mathrm{~mL}$ thiobarbituric acid/trichloroacetic acid solution $(20 \mathrm{mM}$ TBA $/ 15 \%$, w $/ v$ ) were added to the tubes. The mixture was vortexed and then incubated in a $90^{\circ} \mathrm{C}$ boiling water bath for $15 \mathrm{~min}$ to develop color. The sample was cooled in cold water for $10 \mathrm{~min}$, and centrifuged for $15 \mathrm{~min}$ at $3,000 \mathrm{~g}$. The absorbance of the resulting supernatant solution was determined at $531 \mathrm{~nm}$ against a blank containing all the reagents minus the sample. One $\mathrm{ml}$ of distilled water was added to test tube and mixed with $2 \mathrm{~mL}$ of TBA/TCA solution for blank sample. The TBARS was determined in triplicate on each pork belly product. The amount of color was measured in a UV spectrophotome- ter (T60 U., Karaltay Scientific Instruments Co., China). The results were expressed as $\mathrm{mg}$ malonaldehyde $/ \mathrm{kg}$ sample.

\section{Fatty acids analysis}

Total fat for fatty acid analysis was extracted according to the method of Folch et al. (1957). After thawing the samples, the lipids in a $5 \mathrm{~g}$ sample were extracted in chloroform/methanol (2:1), with BHT as an antioxidant (Bligh and Dyer, 1959). The methyl esters from fatty acids (FAMES) were formed using a $\mathrm{KOH}$ solution in methanol. The fatty acid methyl esters (FAME) were extracted with water and hexane. The top hexane layer containing FAME was dehydrated through the anhydrous $\mathrm{Na}_{2} \mathrm{SO}_{4}$. The extracted and dehydrated hexane was transferred to a vial to be analyzed.

Separation and quantification of the fatty acid methyl esters was carried out using a gas chromatograph (GC, Agilent $7890 \mathrm{~N}$, Agilent Technologies Seoul, Korea) equipped with a flame ionization detector automatic sample injector HP 7693, and using a DB-WAX fused silica capillary column $(30 \mathrm{~m}, 0.25 \mathrm{~mm}$ i.d., $0.2 \mathrm{~mm}$ film thickness, Agilent Technologies Seoul, Korea). Helium was used as carrier gas at linear flow of $1 \mathrm{~mL} / \mathrm{min}$ and the injection volume was $1 \mu \mathrm{L}$. The oven temperature was initially held at $180^{\circ} \mathrm{C}$ for $1 \mathrm{~min}$ then increased at $2.5^{\circ} \mathrm{C} /$ min to $230^{\circ} \mathrm{C}$ and held for $12 \mathrm{~min}$. The injector (split mode) and detector temperatures were maintained at $280^{\circ} \mathrm{C}$. Linoleic acid (C18:2) was used as an internal standard (catalogue number H3500, Sigma-Aldrich Inc. USA). The FAME in the total lipids were identified by comparison of the retention times with those of a standard FAME mixture (SuplecoTM 37 Component FAME Mix, Catalogue number 47885-UP, Lot number, LB-85684. Sigma-Aldrich Inc., USA). Fatty acids were expressed as a percentage of total fatty acids identified and grouped as follows: SFA, MUFA and PUFA. PUFA/SFA and n-6/n-3 ratios were calculated.

\section{Free amino acids analysis}

The free amino acid composition was determined by using a modification of the HPLC method described by Bidlingmeyer et al. (1984). The meat was defatted by solvent extraction, and then hydrolyzed with $6 \mathrm{~N} \mathrm{HCl}$ in a vacuum-sealed tube for $24 \mathrm{~h}$ at $110^{\circ} \mathrm{C}$, centrifuged and dried under vacuum for at least $1.5 \mathrm{~h}$. The $\mathrm{pH}$ was adjusted by adding $20 \mathrm{~mL}$ ethanol:water:triethylamine (2:2:1) and the sample dried as before. The samples were derivatised by adding $20 \mu \mathrm{L}$ ethanol:water:triethylamine:phenylisoth- 
iocyanate $(7: 1: 1: 1)$ at room temperature $\left(26^{\circ} \mathrm{C}\right)$ for 10 min and then dried under vacuum for at least $3 \mathrm{~h}$. The sample was re-suspended in $200 \mu \mathrm{L}$ Picotag (Waters, USA), from which $8 \mu \mathrm{L}$ were then injected into an HPLC (Waters HPLC column, Novapak C18. 60 Angstrom, 4 $\mu \mathrm{m}, 3.9 \times 150 \mathrm{~mm})$. Separation was by using buffers: A (sodium acetate, $\mathrm{pH} 6.4,5000 \mathrm{ppm}$ EDTA, triethylamine $(1: 2,000)$ and $6 \%, \mathrm{v} / \mathrm{v}$, acetonitrile) and $\mathrm{B}(60 \%, \mathrm{v} / \mathrm{v}$, acetonitrile and 5,000 ppm EDTA). A 1525 HPLC with a binary gradient delivery, 717 auto-sampler and injector, 1500 column heater and 2487 dual wavelength UV detector were the equipment used in the analysis by Breeze software Z (Waters, USA). Accuracy and repeatability of this analysis is ensured by the inclusion of a control sample of known amino acid composition with the samples prior to hydrolysis.

\section{Sensory evaluations}

The samples were cut into a size $(20 \times 20 \times 10 \mathrm{~mm})$ and were cooked in electrical grill (Nova EMG-533, 1,400 W, Evergreen, Korea) at $100^{\circ} \mathrm{C}$ for $1 \mathrm{~min}$. During the sensory training sessions there was both discussion and sensory assessment of representative samples. The attributes of color, flavor, juiciness, tenderness, and acceptability were assessed. The sensory scores were evaluated independently by 20 trained sensory panelists for random cubes of each sample using a nine-point hedonic scale, varying from dislike/weak extremely (score 1) to like/strong extremely (score 9). The mean value from three repeated measurements was determined.

\section{Statistical methods}

An analysis of variance were performed on all the variables measured using the General Linear Model (GLM) procedure of the SAS statistical package (2008). The Duncan's multiple range test $(p<0.05)$ was used to determine differences among the treatment means.

\section{Results and Discussion}

\section{Chemical and physical characteristics}

Pork quality characteristics in the bellies of two-way crossbreeding pigs are presented in Table 1. Crossbred differences in $\mathrm{pH}$ were significant $(p<0.05)$ in the belly muscles. The $\mathrm{pH}$ values of the bellies were lower in YC than in the other crosses $(p<0.05)$. Kim et al. (2007) reported that the $\mathrm{pH}$ values of pork bellies in Berkshirex Duroc showed higher than those in Yorkshire $\times$ Landrace $\times$ Berkshire and Yorkshire $\times$ Landrace $\times$ Duroc.
As presented in Table 1, moisture contents of the bellies significantly lower in the YB pigs with the respect to the other crosses $(p<0.05)$. YC had the highest moisture content. A previous study showed that the water content of pork bellies was higher in Berkshire than the other breeds (Kang et al., 2011). In case of fat contents, YB was the highest value. But, there were no significant differences in fat contents in the bellies among the crossbreeding pigs. Kim et al. (2007) investigated that there were no significant differences in moisture and fat contents in the bellies among the crossbreeding pigs, and the moisture of pork bellies ranged from $35.6 \%$ to $54.1 \%$ and fat of those ranged from $26.8 \%$ to $40.8 \%$, which is similar to the present results, where intramuscular fat content of twoway pig crossbreds ranged from $27.24 \%$ to $32.58 \%$ in bellies.

As shown in Table 1, the cooking loss of the bellies were lower in YB than in the other crosses $(p<0.05)$. This may be due to the crossbreeding effect on the crossbreedspecific relationship between each trait. Ryu et al. (2008) suggested that the Berkshire breed has a significantly lower drip loss compared with Landrace, Yorkshire, and the crossbred pigs. Goodwin (2004) reported that loins from Berkshire pigs had less cooking loss than those from landrace ones. NPPC (1995) reported that Berkshire was the most excellent breed in drip and cooking loss. However, Fat contents, the drip loss, WHC, and shear force values of samples were inconsistent depending on the pig crossbred. Kim et al. (2006) reported WHC of pork bellies among the crossbreeding ranged from $52 \%$ to $79 \%$, which is similar to the present results. Warner-Bratzler shear force value is a moderate indicator of tenderness and texture (Essen-Gustavsson et al., 1994). Interestingly, as shear force increased, off flavors, metallic flavors, and

Table 1. Pork quality traits of bellies from different two-way crossbred

\begin{tabular}{ccccc}
\hline \hline & \multicolumn{3}{c}{ Crossbred $^{1}$} & \multirow{2}{*}{ SEM $^{2}$} \\
\cline { 2 - 4 } & YL & YB & YC & \\
\hline pH & $5.82^{\mathrm{a}}$ & $5.77^{\mathrm{a}}$ & $5.60^{\mathrm{b}}$ & 0.03 \\
Moisture (\%) & $55.68^{\mathrm{a}}$ & $48.78^{\mathrm{b}}$ & $57.32^{\mathrm{a}}$ & 1.53 \\
Fat (\%) & 31.46 & 32.58 & 27.24 & 1.14 \\
Drip loss (\%) & 0.60 & 0.42 & 0.53 & 0.06 \\
Cooking loss (\%) & $10.82^{\mathrm{a}}$ & $6.77^{\mathrm{b}}$ & $11.33^{\mathrm{a}}$ & 0.66 \\
Water holding capacity & 76.59 & 79.17 & 76.76 & 1.13 \\
Shear force (kgf) & 5.44 & 6.01 & 5.65 & 0.31 \\
\hline
\end{tabular}

${ }^{1}$ YL: YorkshireLandrace, YB: YorkshireBerkshire, YC: Yorkshire Chester

${ }^{2}$ Standard error of the means $(n=5)$.

${ }^{\mathrm{a}-\mathrm{b}}$ Figures with different letters within the same row differ significantly $(p<0.05)$. 
chewiness increased while sweetness decreased suggesting that genetic line may have some indirect impact on flavor. It has been well documented that intramuscular fat reduces shear force (Essen-Gustavsson et al., 1994). Jin et al. (2005) reported that YBB had lower shear force value and cooking loss than LYD. Meat color values of bellies from different two-way crossbreeding bellies were given in Table 2. The statistical analysis did not reveal any significant difference between crossbred in terms of the meat color of the bellies.

TBARS value is the most common indicator used to measure the degree of lipid oxidation in meat products (Chen et al., 2004). As presented in Table 3, TBARS value increased significantly during the refrigerated storage for all three crossbreds $(p<0.05)$. It is normally accepted that TBARS value increases in meat with increasing storage time (Yang et al., 2009). The TBARS value in YB was significantly higher than the others after 14 days of storage. The results might be due to the fact that Berkshire breed had more oxidative fiber than others, which are consequently reflected higher TBARS on YB (Hwang et al., 2005).

\section{Fatty acid composition}

Fatty acid composition in the belly muscles of two-way crossbreeding bellies are presented in Table 4 . The major fatty acids in the belly muscles (listed from most prevalent to least) were oleic (C18:1n-9), palmitic (C16:0), stearic (C18:0), linoleic (C18:2n-6), vaccenic (C18:1n-7), palmitoleic (C16:1), and myristic (C14:0) acids. These seven fatty acids accounted for over $95 \%$ of the total fatty acids in the intramuscular fat (IMF). Minor fatty acids were lauric (C12:0), linolenic (C18:3), arachidonic (C20: 4n-6), EPA (C20:5n-3), and DHA (C22:6n-3) acids. Crossbred effects on fatty acid composition were significant $(p<0.05)$ for most of the fatty acid composition. In particular, YL bellies had higher percentage of stearic acid (C18:0), oleic acid (C18:1n-9), and MUFA than the other crosses, while YB and YC bellies had higher percentage of myristic acid (C14:0), linoleic acid (C18:2n6), linolenic acid (C18:3), and n-6 fatty acids in belly muscles than YL bellies $(p<0.05)$.

PUFA content was significantly higher in belly muscles from YC than from YL, which showed the highest percentages of $\mathrm{C} 18: 2 \mathrm{n}-6, \mathrm{C} 18: 3$, and $\mathrm{C} 22: 6 \mathrm{n}-3$. The degree of unsaturation of fatty acids indicates the sum of MUFA and PUFA contents. MUFA was mostly composed of oleic acid (C18:1n-9). The sum of MUFA and PUFA is associated with a possibility of oxidation, rancidity, soft-
Table 2. CIE color values of bellies from different two-way crossbred

\begin{tabular}{ccccc}
\hline \hline & \multicolumn{3}{c}{ Crossbred $^{1}$} & \multirow{2}{*}{ SEM $^{2}$} \\
\cline { 2 - 4 } & YL & YB & YC & \\
\hline CIE L* & 65.39 & 63.39 & 63.77 & 0.51 \\
CIE a* $^{*}$ & 8.20 & 8.87 & 8.44 & 0.21 \\
CIE b* $^{*}$ & 11.06 & 10.54 & 10.58 & 0.16 \\
\hline
\end{tabular}

${ }^{1}$ YL: YorkshireLandrace, YB: YorkshireBerkshire, YC: Yorkshire Chester

${ }^{2}$ Standard error of the means $(n=5)$.

Table 3. TBARS values (mg MDA/kg meat) of bellies from different two-way crossbred during storage

\begin{tabular}{ccccc}
\hline Crossbred $^{1}$ & \multicolumn{3}{c}{ Storage (days) } & \multirow{2}{*}{ SEM $^{1}$} \\
\cline { 2 - 4 } & 0 & 7 & 14 & \\
\hline YL & $0.32^{\mathrm{C}}$ & $0.74^{\mathrm{B}}$ & $1.06^{\mathrm{bA}}$ & 0.09 \\
YB & $0.29^{\mathrm{C}}$ & $0.66^{\mathrm{B}}$ & $1.57^{\mathrm{aA}}$ & 0.15 \\
YC & $0.30^{\mathrm{C}}$ & $0.77^{\mathrm{B}}$ & $1.13^{\mathrm{bA}}$ & 0.09 \\
SEM & 0.01 & 0.03 & 0.08 & \\
\hline
\end{tabular}

${ }^{1}$ YL: YorkshireLandrace, YB: YorkshireBerkshire, YC: Yorkshire Chester

${ }^{2}$ Standard error of the means $(n=5)$.

${ }^{\mathrm{a}-\mathrm{b}}$ Figures with different letters within the same column differ significantly $(p<0.05)$.

${ }^{A-C}$ Figures with different letters within the same row differ significantly $(p<0.05)$.

Table 4. Fatty acid composition (\%) of bellies from different two-way crossbred

\begin{tabular}{|c|c|c|c|c|}
\hline & \multicolumn{3}{|c|}{ Crossbred $^{1}$} & \multirow{2}{*}{$\mathrm{SEM}^{2}$} \\
\hline & YL & YB & $\mathrm{YC}$ & \\
\hline C12:0 & $0.08^{b}$ & $0.15^{\mathrm{a}}$ & $0.09^{\mathrm{ab}}$ & 0.02 \\
\hline C14:0 & $1.30^{\mathrm{b}}$ & $1.54^{\mathrm{a}}$ & $1.62^{\mathrm{a}}$ & 0.05 \\
\hline C16:0 & 22.21 & 22.52 & 22.16 & 0.17 \\
\hline C16:1 & 2.32 & 2.70 & 2.74 & 0.10 \\
\hline C18:0 & $12.21^{\mathrm{a}}$ & $10.81^{\mathrm{b}}$ & $10.64^{\mathrm{b}}$ & 0.28 \\
\hline C18:1n-9 & $44.13^{\mathrm{a}}$ & $42.49^{\mathrm{ab}}$ & $41.64^{b}$ & 0.28 \\
\hline C18:1n-7 & $3.11^{\mathrm{b}}$ & $3.33^{\mathrm{a}}$ & $3.14^{\mathrm{ab}}$ & 0.43 \\
\hline C18:2n-6 & $10.02^{\mathrm{b}}$ & $11.79^{\mathrm{a}}$ & $12.62^{\mathrm{a}}$ & 0.04 \\
\hline C18:3 & $0.51^{\mathrm{b}}$ & $0.62^{\mathrm{a}}$ & $0.67^{\mathrm{a}}$ & 0.40 \\
\hline$C 20: 4 n-6$ & 0.79 & 0.79 & 0.83 & 0.02 \\
\hline$C 20: 5 n-3$ & 0.79 & 0.88 & 0.82 & 0.05 \\
\hline$C 22: 6 n-3$ & $0.59^{\mathrm{b}}$ & $0.48^{b}$ & $0.81^{\mathrm{a}}$ & 0.05 \\
\hline SFA & 35.79 & 35.02 & 34.50 & 0.08 \\
\hline MUFA & $49.56^{\mathrm{a}}$ & $48.56^{\mathrm{ab}}$ & $46.85^{b}$ & 0.29 \\
\hline PUFA & $12.59^{\mathrm{b}}$ & $14.28^{a b}$ & $15.66^{\mathrm{a}}$ & 0.47 \\
\hline $\mathrm{P} / \mathrm{S}$ & $0.35^{\mathrm{b}}$ & $0.41^{\mathrm{ab}}$ & $0.45^{\mathrm{a}}$ & 0.10 \\
\hline$n-6$ & $10.81^{b}$ & $12.66^{\mathrm{a}}$ & $13.45^{\mathrm{a}}$ & 0.47 \\
\hline$n-3$ & 1.19 & 1.14 & 1.40 & 0.40 \\
\hline$n-6 / n-3$ & 9.75 & 11.21 & 11.02 & 0.02 \\
\hline
\end{tabular}

${ }^{1}$ YL: YorkshireLandrace, YB: YorkshireBerkshire, YC: Yorkshire Chester

${ }^{2}$ Standard error of the means $(n=5)$.

${ }^{3}$ SFA: saturated fatty acids, MUFA: monosaturated fatty acids, PUFA: polysaturated fatty acids

${ }^{\mathrm{a}-\mathrm{b}}$ Figures with different letters within the same row differ significantly $(p<0.05)$. 
ness, and texture of the fat, as the number of double bonds in fatty acids increases and their melting point and oxidative stability are reduced (Wood et al., 1999). MUFA and PUFA contents significantly differed between crossbreds. Differences in fatty acid composition between different crossbred could be attributed different causes by a different content of IMF and a different potential for endogenous synthesis of fatty acids (Ramirez and Cava, 2007). Fatty acid composition is affected by genetic and environmental factors, which include diet, sex, age, and genotype (Brewer et al., 2001; Cameron and Enser, 1991). Several studies have reported that the fatty acid composition and fat tissue of pork can be modified by changing the feeding system (Zhang et al., 2007), because the pig is a single stomached animal and the absorbed dietary fatty acids from the small intestine are utilized or deposited as an intact form in the muscle or lipid tissue of the animal (Wood et al., 1999). It has been demonstrated that pig breed have different fatty acid profile (Wood et al., 2003) and breed and fatty acid composition generate different flavor species such as free amino acids (Elmore $e t$ al., 2004).

Meat is a major source of fat including SFA in the human diet (Wood et al., 2003). Generally, excessive intake of SFA has been considered as the main factor for cancer and coronary heart disease, although $\mathrm{C} 18: 0$ is considered as a neutral fatty acid (Webb and O'Neill, 2008). WHO recommends reducing the intake of SFA and increasing the intake of $n-3$ PUFA. The minimum $\mathrm{P} / \mathrm{S}$ ratio for human nutrition is at least 0.45 (Simopoulos, 2004) and generally should be around 0.7 (Raes et al., 2003). In the present, the $\mathrm{P} / \mathrm{S}$ ratios in different crossbreds were lower than in the above recommendation. According to Scollan et al. (2006), high values of PUFA:SFA ratios is due to higher levels of linoleic acid (C18:2n-6) in pig Longissimus dorsi muscle. In n-6:n-3 ratio, a higher value was also found compared to the target of less than 4 (Scollan et al., 2006). However, it is difficult to reduce this value in pigs due to the high level of $\mathrm{C} 18: 2 \mathrm{n}-6$ which produces a high $n-6: n-3$ ratio, the $n-6: n-3$ ratio of pig muscle is high compared to that of ruminants (Wood et al., 2008).

\section{Free amino acids}

Free amino acids are known to be important in taste and flavor development (Aristoy and Toldra, 1995; Kato et al., 1989; Toldra, 1998). Lysine, threonine, valine, methionine, isoluecine, leucine, phenylalanine, lysine, and histidine have been known as essential amino acid, whereas arginine, aspartic acid, serine, glutamic acid, glycine, thyrosine, alanine have been known as non-essential amino acid. Free amino acid composition in pork bellies of twoway crossbreeding is given in Table 5. Except for a few amino acids, crossbred differences in amino acid composition were significant $(p<0.05)$ in the belly muscles. The free amino acid with the highest concentration in bellies of two-way crossbreeding pigs is cysteine. Alanine, aspartic acid, cysteine, histidine, and threonine were the most abundant free amino acids in pork bellies. Alanine, glutamic acid, glycine, histidine, isoluecine, leucine, lysine, methionine, phenylalanine, serine, thyrosine, valine, threonine, and proline in bellies were much higher in the YB pigs with the respect to the other crosses $(p<0.05)$. YB pigs had lower percentage of arginine in bellies than the other crosses $(p<0.05)$.

In the present study, YB pigs had higher percentage of glutamic acid known for umami taste in bellies than the other crosses $(p<0.05)$, whereas YB pigs had lower percentage of arginine known for bitter taste in bellies. Glutamic acid is one of the amino acids responsible for the meat flavor and it is associated with the "umami" term, which is used to describe agreeable slightly sweet and sour tastes that produce the so-called "mouth satisfaction" (Maga, 1998). The sensory properties of free amino

Table 5. Free amino acid composition (\%) of bellies from different two-way crossbred

\begin{tabular}{ccccc}
\hline \hline & \multicolumn{3}{c}{ Crossbred $^{\mathrm{I}}$} & \multirow{2}{*}{ SEM $^{2}$} \\
\cline { 2 - 4 } & YL & YB & YC & \\
\hline Ala & $23.11^{\mathrm{b}}(\mathrm{mg} / 100 \mathrm{~g}$ muscle $)$ \\
Arg & $10.82^{\mathrm{a}}$ & $6.40^{\mathrm{a}}$ & $22.13^{\mathrm{b}}$ & 2.47 \\
Asp & 76.59 & 79.17 & $11.33^{\mathrm{a}}$ & 1.35 \\
Cys & 236.74 & 261.12 & 262.66 & 0.45 \\
Glu & $4.89^{\mathrm{b}}$ & $9.02^{\mathrm{a}}$ & $6.37^{\mathrm{ab}}$ & 10.10 \\
Gly & $11.45^{\mathrm{b}}$ & $17.83^{\mathrm{a}}$ & $11.22^{\mathrm{b}}$ & 0.68 \\
His & $24.64^{\mathrm{b}}$ & $56.72^{\mathrm{a}}$ & $20.40^{\mathrm{b}}$ & 4.03 \\
Ile & $3.00^{\mathrm{b}}$ & $5.04^{\mathrm{a}}$ & $2.84^{\mathrm{b}}$ & 0.32 \\
Leu & $5.60^{\mathrm{b}}$ & $8.70^{\mathrm{a}}$ & $5.16^{\mathrm{b}}$ & 0.56 \\
Lys & $2.26^{\mathrm{b}}$ & $7.17^{\mathrm{a}}$ & $1.05^{\mathrm{b}}$ & 0.93 \\
Met & $2.95^{\mathrm{ab}}$ & $4.20^{\mathrm{a}}$ & $2.75^{\mathrm{b}}$ & 0.29 \\
Phe & $4.38^{\mathrm{b}}$ & $5.91^{\mathrm{a}}$ & $4.24^{\mathrm{b}}$ & 0.30 \\
Pro & $7.84^{\mathrm{b}}$ & $14.30^{\mathrm{a}}$ & $9.93^{\mathrm{b}}$ & 0.94 \\
Ser & $3.47^{\mathrm{b}}$ & $8.33^{\mathrm{a}}$ & $2.70^{\mathrm{b}}$ & 0.87 \\
Thr & $14.60^{\mathrm{a}}$ & $23.13^{\mathrm{a}}$ & $13.67^{\mathrm{b}}$ & 1.23 \\
Tyr & $1.27^{\mathrm{b}}$ & $3.42^{\mathrm{a}}$ & $0.88^{\mathrm{b}}$ & 0.35 \\
Val & $5.63^{\mathrm{b}}$ & $9.28^{\mathrm{a}}$ & $5.79^{\mathrm{b}}$ & 0.56 \\
\hline
\end{tabular}

${ }^{1}$ YL: YorkshireLandrace, YB: YorkshireBerkshire, YC: Yorkshire Chester

${ }^{2}$ Standard error of the means $(n=5)$.

${ }^{\mathrm{a}-\mathrm{b}}$ Figures with different letters within the same row differ significantly $(p<0.05)$. 
acids have been well established; glutamic and aspartic acid showing pleasantly fresh or umami taste, glycine, alanine, lysine and serine being sweet, arginine, leucine, isoleucine, valine, phenylalanine, methionine and histidine being bitter, lysine and proline contributing sweet and other showing sour or salty taste (Zhu and Hu, 1993). Cornet and Bousset (1999) noted that the accumulation of some free amino acids could result in undesirable flavor and cause decreases in the WHC of the meat. However, free amino acids are of great importance in eating quality due to their specific tastes (Nishimura and Kato, 1988).

\section{Sensory evaluation}

Sensory evaluation in the muscles of two-way crossbreeding pigs is presented in Table 6 . Sensory evaluation was affected by crossbreeding in belly muscles. Color, flavor, tenderness, juiciness and acceptability were higher in YC than the others in belly muscles $(p<0.05)$. All sensory evaluation was the lowest in YB in bellies $(p<0.05)$. These results may explain some of variations in sensory scores between muscles of the crossbreds. This result showed YB could be more susceptible to lipid oxidation resulting in the development of rancidity.

Flavor is one of the most important qualities of meat and meat products. Raw meat possesses only a serum-like flavor, with the characteristic flavor components being produced during the heating process (Hilmes and Fischer, 1997). In addition, the amount and type of fat in meat influence two major components of meat quality, i.e., tenderness and flavor (Wood et al., 1999). In general, the intramuscular fat content correlates with meat tenderness (Chmurzyńska, 2006; Wood et al., 2003). Lipids are also one of the major flavor precursors in meat (Mottram and Edward, 1983). Basically, high proportions of PUFA reduce the oxidative stability of lipids, which could have

Table 6. Sensory evaluation of bellies from different two-way crossbred

\begin{tabular}{ccccc}
\hline \hline \multirow{2}{*}{ Attribute $^{1}$} & \multicolumn{3}{c}{ Crossbred $^{2}$} & \multirow{2}{*}{ SEM $^{3}$} \\
\cline { 2 - 4 } & YL & YB & YC & \\
\hline Color & $5.27^{\mathrm{b}}$ & $4.87^{\mathrm{c}}$ & $6.13^{\mathrm{a}}$ & 0.19 \\
Flavor & $5.40^{\mathrm{b}}$ & $2.93^{\mathrm{c}}$ & $7.13^{\mathrm{a}}$ & 0.64 \\
Tenderness & $5.93^{\mathrm{b}}$ & $3.87^{\mathrm{c}}$ & $7.27^{\mathrm{a}}$ & 0.50 \\
Juiciness & $5.93^{\mathrm{b}}$ & $4.27^{\mathrm{c}}$ & $7.27^{\mathrm{a}}$ & 0.44 \\
Acceptability & $5.80^{\mathrm{b}}$ & $3.60^{\mathrm{c}}$ & $7.50^{\mathrm{a}}$ & 0.57 \\
\hline
\end{tabular}

${ }^{1} 1$ : extremely bad $\sim$ 9: extremely good.

${ }^{2}$ YL: YorkshireLandrace, YB: YorkshireBerkshire, YC: Yorkshire Chester

${ }^{3}$ Standard error of the means $(n=5)$.

${ }^{\mathrm{a}-\mathrm{c}}$ Figures with different letters within the same row differ significantly $(p<0.05)$. negative effects on the sensory characteristics of fresh meat and meat products (Nawar, 1996).

The sensory evaluation could be also affected by free amino acid composition. Basically, low sensory scores in meat were due to its lower aspartic and glutamic acids, which could have negative effects on the sensory traits of pork (Kato et al., 1989). However, low flavor scores in YB could not be explained by the profiles fatty acids or free amino acid. YC bellies produced more tender and juicy meat. Two-way crossbreeding significantly affected fatty acid and free amino acid composition from the belly muscles. However, the reasons for these crossbreeding differences were so complex. Nevertheless, further research using pig crossbreds is required to indentify the correlation between the sensory and physicochemical values.

\section{Acknowledgements}

This study was supported by the research program from IPET (110041-3), Ministry for Food, Agriculture, Forestry and Fisheries, Republic of Korea.

\section{References}

1. Ahn. D. U., Olson, D. G., Jo. C., Chen. X., Wu. C. and Lee, J. I. (1998) Effect of muscle type, packaging, and irradiation on lipid oxidation, volatile production, and color in raw pork patties. Meat Sci. 49, 27-39.

2. Alasnier, C., ReÂmignon, H., and Gandemer, G. (1996) Lipid characteristics associated with oxidative and glycolytic fibres in rabbit muscles. Meat Sci. 43, 213-224.

3. AOAC (2000) Official methods of analysis. 17th ed, Association of Official Analytical Chemists, Gaithersburg, MD.

4. Aristoy, M. C. and Toldra, F. (1995) Deproteinization techniques for amino acid analysis in fresh pork muscle and drycured ham. J. Agric. Food Chem. 39, 1792-1795.

5. Bennet, G. L., Tess, W. M., Dickerson, G. E., and Johnson, R. K. (1983) Simulation of breed and crossbreeding effects on costs of pork production. J. Anim. Sci. 56, 801-813.

6. Bidlingmeyer, B., Cohen, S. A., and Tarvin, T. L. (1984) Rapid analysis of amino acids using pre-column derivatisation. J. Chromatogra. 336, 93-104.

7. Bligh, E. G. and Dyer, W. J. (1959) A rapid method of total lipid extraction and purification. Canadian J. Biochem. Physiol. 37, 911-914.

8. Brewer, M. S., Zhu, L. G., and McKeith, F. K. (2001) Marbling effects on quality characteristics of pork loin chops: Consumer purchase intent, visual and sensory characteristics. Meat Sci. 59, 153-163.

9. Cameron, N. D. and Enser, M. B. (1991) Fatty acid composition of lipid in longissimus dorsi muscle of Duroc and British Landrace pigs and its relationship with eating quality. Meat Sci. 29, 295-307. 
10. Chen, W. S., Lin, D. C., and Chen, M. T. (2004) Determination of quality changes throughout processing steps in Chinese-style pork jerky. Asian-Aust. J. Anim. Sci. 17, 700-704.

11. Chmurzyńska, A. (2006) The multigene family of fatty acidbinding proteins (FABPs): Function, structure and polymorphism. J. Appl. Genet. 47, 39-48.

12. Cornet, M. and Bousset, J. (1999) Free amino acid and dipeptides in porcine muscles: Differences between 'red' and 'white' muscles. Meat Sci. 51, 215-219.

13. Elmore, J. S., Warren, H. E., Mottram, D. S., Scollan, N. D., Enser, M., Richardson, R. I., and Wood, J. D. (2004) A comparison of the aroma volatiles and fatty acid compositions of grilled beef muscle from Aberdeen Angus and Holstein-Friesian steers fed diets based on silage or concentrates. Meat Sci. 68, 27-33.

14. Essen-Gustavsson, B., Karlsson, A., Lundstrom, K. and Enflat, A. C. (1994) Intramuscular fat and muscle fibre lipid contents in halothane-gene-free pigs fed high or low protein diets and its relation to meat quality. Meat Sci. 38, 269-277.

15. Folch, J., Lee, M., and Sloane-Stanley, G. H. (1957). A simple method for the isolation and purification of total lipids from animal tissues. J. Biol. Chem. 226, 497-507.

16. Goodwin, R. N. (2004) Growth, carcass, and meat quality trait performance of pure breeds. In: Proceedings of national swine improvement federation. NSIF (Vol. 29, pp. 47-56). 910 December 2004, Ames, IA.

17. Hwang, I. H., Polkinghorne, R., Lee, J. M., and Thompson, J. M. (2008) Demographic and design effects on beef sensory scores given by Korean and Australian consumers. Aust. J. Exptl. Agri. 48, 1387-1395.

18. Hilmes, C. and Fischer, A. (1997) Role of amino acids and glucose in development of off-flavors in liver sausage during heat processing. Meat Sci. 47, 249-258.

19. Hong, K. C., Kim, B. C., Son, Y. S., and Kom, B. K. (2001) Effects of the mating system on fattening performance and meat quality in commercial pigs. J. Anim. Sci. Technol. 43, 139-148.

20. Jin, S. K., Kim, I. S., Song, Y. M., Hur, S. J., Ha, J. H., and Ha, K. H. (2005) Effects of crossbreed method on meat quality in pigs. J. Anim. Sci. Technol. 47, 457-464.

21. Kang, H. S., Seo, K. S., Kim, K. T. and Nam, K. C. (2011) Comparison of pork quality characteristics of different parts from domesticated pig species. Korean J. Food Sci. An. 31, 921-927.

22. Kato, H., Rhue, M. R., and Nishimura, T. (1989) Role of free amino acids and peptides in food taste. In: Flavor Chemistry. Trends and Developments. Teranishi, R., Buttery, R. G. and Shahidi, F. (eds) ACS Symp Series 388, American Chem. Soc., Washington, DC, pp. 158-174.

23. Kim, J. H., Park, B. Y., Yoo, Y. M., Cho, S. H., Hwang, I. H., Seong, P. N., Hah, K. H. and Lee, J. M. (2006) Characteristics of carcass and meat quality for landrace, Yorkshire, duroc and their crossbreeds. J. Anim. Sci. Technol. 48, 101-106.

24. Kim, H. S., Yang, H. S., Lee, J. I., Joo, S. T., Jeon, J. T., and Lee, J. G. (2007) Effects of the mating system on retail cut yield and meat quality in commercial pigs. J. Anim. Sci. Technol. 49, 379-386.
25. Langlois, A. and Minvielle, F. (1989) Comparisons of threeway and backcross swine. J. Anim. Sci. 67, 2018-2024.

26. Leseigneur-Meynier, A. and Gandemer, G. (1991) Lipid composition of pork muscle in relation to the metabolic type of the fibres. Meat Sci. 29, 229-241.

27. Maga, J. A. (1998) Umami flavour of meat. In: Flavour of meat products and seafood. Shahidi, F. (ed.) Chapman \& Hall, London, pp. 197-216.

28. Mottram, D. S. and Edwards, R. A. (1983) The role of triglycerides and phospholipids in the aroma of cooked beef. $J$. Sci. Food Agric., 34, 517-522.

29. National Pork Producers Council (NPPC). (1995) National genetic evaluation program. IA, USA: Des Moines.

30. Nawar, W. W. (1996) Lipids. In: Food chemistry. Fennema, O. R. (ed.) Marcel Dekker, Inc., NY, pp. 225-319.

31. Newcom, D. W., Stalder, K. J., Baas, T. J., Goodwin, R. N., Parrish, F. C., and Wiegand, B. R. (2004) Breed differences and genetic parameters of myoglobin concentration in porcine longissimus muscle. J. Anim. Sci. 82, 2264-2268.

32. Nishimura, T. and Kato, H. (1988) Taste of free amino acids and peptides. Food Rev. Int. 4, 175-194.

33. Raes, K., Balcaen, A., Dirinck, P., De Winne, A., Claeys, E., and Demeyer, D. (2003) Meat quality, fatty acid composition and flavour analysis in Belgian retail beef. Meat Sci. 65, 1237-1246.

34. Ramirez, R. and Cava, R. (2007) Carcass composition and meat quality of three different Iberian X Duroc genotype pigs. Meat Sci. 75, 388-396.

35. Ruusunen, R., Puolanne, E., Sevon-Aimonen, M., Partanen, K., Voutila, L., and Niemi, J. (2012) Carcass and meat quality traits of four different pig crosses. Meat Sci. 90, 543-547.

36. Ryu, Y. C., Choi, Y. M., Lee, S. H., Shin, H. G., Choe, J. H., and Kim, J. M. (2008) Comparing the histochemical characteristics and meat quality traits of different pig breeds. Meat Sci. 80, 363-369.

37. SAS (2008) SAS/STAT Software for PC. Release 9.2, SAS Institute Inc., Cary, NC, USA.

38. Scollan, N., Hocquette, J. F., Nuernberg, K., Dannenberger, D., Richardson, I., and Moloney, A. (2006) Innovations in beef production systems that enhance the nutritional and health value of beef lipids and their relationship with meat quality. Meat Sci. 74, 17-33.

39. Sellier, P. and Monin, G. (1994) Genetics of pig meat quality. J. Muscle Food 5, 187-219.

40. Simopoulos, A. P. (2004) Omega-6/Omega-3 essential fatty acid ratio and chronic diseases. Food Rev. Int. 20, 77-90.

41. Suzuki, K., Shibata, T., Kadowaki, H., Abe, H., and Toyoshima, T. (2003) Meat quality comparison of Berkshire, Duroc and crossbred pigs sired by Berkshire and Duroc. Meat Sci. 64, $35-42$.

42. Toldra, F. (1998) Proteolysis and lipolysis in flavor development of dry-cured meat products. Meat Sci. 49, 101-110.

43. Uttaro, B. E., Ball, R.O., Dick, P., Rae, W., Vessie, G., and Jeremiah, L. E. (1993) Effect of ractopamine and sex on growth, carcass characteristics, processing yield, and meat quality characteristics of crossbred swine. J. Anim. Sci. 71, 2439-2449.

44. Webb, E. C. and O'Neill, H. A. (2008) The animal fat para- 
dox and meat quality. Meat Sci. 80, 28-36.

45. Wood, J. D., Enser, M., Fisher, A. V., Nute, G. R., Richardson, R. I., and Sheard, P. R. (1999) Manipulating meat quality and composition. Proceed. Nutr. Soc. 58, 363-370.

46. Wood, J. D., Richardson, R. I., Nute, G. R., Fisher, A. V., Campo, M. M., and Kasapidou, E. (2003) Effects of fatty acids on meat quality: A review. Meat Sci. 66, 21-32.

47. Wood, J. D., Enser, M., Fisher, A. V., Nute, G. R., Sheard, P. R., and Richardson, R. I. (2008) Fat deposition, fatty acid composition and meat quality: A review. Meat Sci. 78, 343358.
48. Yang, H. S., Hwang, Y. H., Joo, S. T. and Park. G. B. (2009) The physicochemical and microbiological characteristics of pork jerky in comparison to beef jerky. Meat Sci. 82, 289294.

49. Zhang, S., Knight, T. J., Stalder, K. J., Goodwin, R. N., Lonergan, S. M., and Beitz, D. C. (2007) Effects of breed, gender, and halothane genotype on fatty acid composition of pork longissimus dorsi muscle. J. Anim. Sci. 85, 583-591.

50. Zhu, S. W. and Hu, J. X. (1993) Studies on Jinhua ham tastes and taste substances. J. Food Sci. 159, 8-11.

$\overline{\text { (Received 2013.1.16/Revised 2013.3.11/Accepted 2013.3.20) }}$ 